\title{
Teaching with Original Problems in the Electrical Exploration Course
}

\author{
D.K. He ${ }^{1}$, S.P. Peng ${ }^{2}$ and G.W. Zhu ${ }^{3}$ \\ China University of Mining and Technology, Beijing 100083, China \\ 1'he_dengke@126.com, ${ }^{2}$ psp@cumtb.edu.cn, ${ }^{3}$ zgw@cumtb.edu.cn
}

\begin{abstract}
Keywords: Teaching Reform; Geophysics; Electrical Exploration; Original Problems; Exercises Teaching.
\end{abstract}

\begin{abstract}
The paper introduced the original problems method to electrical exploration course and proposed its application procedures. The whole procedures consisted of five steps, including characterizing, abstracting, simulating, interpreting and estimating. The original problems teaching will not only check students' learning through exercises training, but also guide students analyzing the original phenomenon and applying knowledge acquired to solve practical projects of industry or living. Consequently, students will be more interesting with learning and be improved on innovation, collaboration and active study under the original problems method.
\end{abstract}

\section{Introduction}

The education method with teaching exercise which is prevailing in the current high school days can help and guide students to master basic knowledge as soon as possible. The main characteristic with exercise teaching is that the teacher constructed the exercises, according with the basic knowledge and the answering way, and asked students to resolve them. The necessities and questions of these exercises are described obviously by their teacher. Only if can students follow the procedures instructed by their teacher, the results expected will be acquired. To be able to solve these exercises, students can master the elementary knowledge easily. It seems not to do exercise is impossible.[1] However, under the pressure by College Entrance Examination, the exercise teaching method has been excessively highlighted and therefore students' consciousness of innovation and skills of problem-solving have not been better trained and improved. When learning the electrical exploration course, which is more comprehensive and practical, students will be in troubles and not know how to do.

The electrical exploration course is one of significant theoretical curricula of the geophysical prospecting. The electrical exploration is one of significant methods in the geophysical prospecting industry and widespread used in resource reconnaissance, hydrological investigation, environmental engineering, and so on. It requires to learn many course advance, such as higher mathematics, partial differential equation, electric field theory, geological science, signal processing, etc. [2] Like other courses of geophysics, the electrical exploration course has the characteristics of both geological science and physics.

Firstly, the material foundation of the electrical exploration is the electromagnetic property and characteristic. These characteristics of minerals, the fundamental and knowledge of electromagnetics must be mastered before learning the electrical exploration course. Secondly, prospecting the stratigraphic structures and rock physics is the main task of electrical exploration. The fundamental and knowledge of geoscience, the work ways of geoscience engineering must be mastered before learning this course, too.

Encountering the elemental knowledge of the two disciplines and their application flexibly, students can't master the required subjects of the electrical exploration course if they will continue to learn them according to exercise teaching. They will not know what the learning object is, which geoscience tasks they need to solve and how to work out. In consideration of these characteristics of geophysics, we introduce the teaching ideal of original problems and implement teaching reform here. 
The original problems method has been researched and applied in teaching courses by many teachers and specialists. Yu divided physical questions as original problems and abstracted problems, and discussed scientific abilities training with the former. [3] Xing proposed the original physical problem teaching is the new view of physical education reform. [4] Then Xing and his students studied several education functions and application of the original physical teaching from many aspects. [5-7] Recently, Zhou et al. discussed the original problem in middle school physical teaching reform [8] and Wang et al. analyzed the value and strategy of the original problem in chemistry teaching [9].

\section{Education methods comparison between the original problems and the teaching exercises}

The original problems are objective physical phenomenon and not abstracted from production and living. The exercises, however, are abstracted, simplified, extracted by teachers from the objective physical phenomenon according to the related basic principles and fundamental knowledge. The background conditions are extracted and transformed to the obvious known parameters, meanwhile, the tasks to be solved are extracted and transformed to the explicit calculated process. The theoretical hypothesis related is complemented by teachers if necessary. As regards the differences about the original problems and teaching exercises, Zhao proposed that a same physical problem arranged for students is not only as the original one accompanied with some suggestions, but also as the mathematical extracted by the teacher. Some students always trained by the latter will be often at a loss in the former situation [10]. The task required in the electrical exploration industry production and the related courses is the former, which is the original one and not calculated as a determined answer but compromised with several recommend proposals. There are many typical cases in the electrical exploration course, such as that a coal corporation wondered there are some water in the mine goaves or not, a west village required extracting the ground water as domestic water but wondered where the ground water are, a corporation wondered a metal mine's occurrence and reserves, and so on. Students will have huge study interesting and the teaching fruits will be more when these original problems from industry and living are thought and discussed by students accompanied with basic principles, fundamental knowledge and working ways lectured by the teacher.

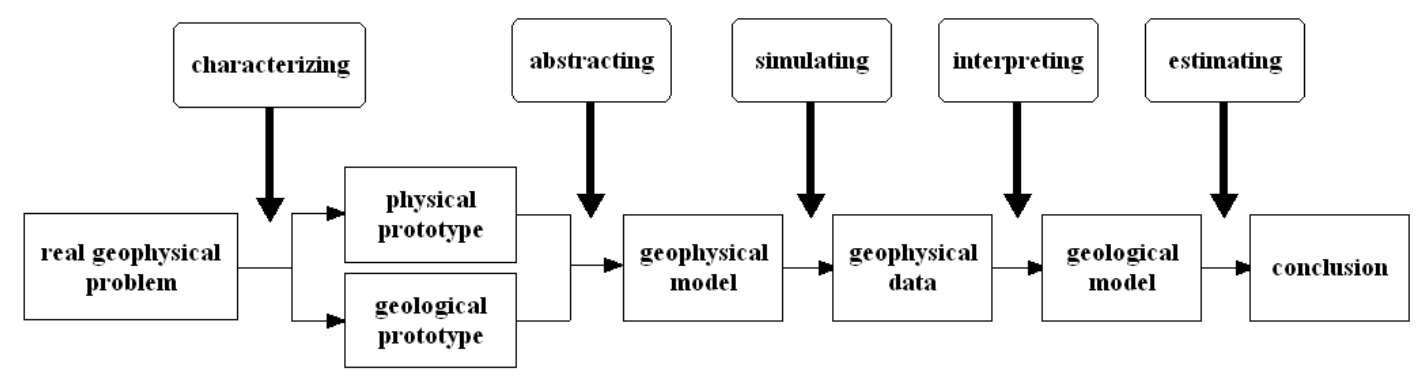

Figure. 1 The working procedure of original problems method

\section{Original problems application procedure in the electrical exploration course}

The exercises teaching demanded students master the series of skills and trick for solving exercises. This learning method needs memory and calculating more, which made many students misunderstanding physical problems as mathematical calculation [11]. Not mastered the essence of physical problems profoundly will badly impede train and advance of students' innovation abilities. The original problems from the industry and living have not been abstracted and simplified, and are full of abundant details and significant realism meanings, however, which can stimulate students' interesting more and accelerate students' innovation abilities. There are the specific working procedures of original problems method as shown in the Fig. 1. 
To beginning with, the original physical model is extracted from the subsurface tectonic model with related rock physical parameters through inspecting, analyzing and describing the geophysical prospecting projects. In the process, students must not only find the geologic structure and rock physics about the research area, but also grasp the topography, meteorological condition, hydrological condition, humanistic background, and so on. Only if one of these conditions is difference, the solving proposal will be difference even though under the same subsurface condition. Consequently, students must organize a work group and collaborate each other in the first step. They will have happy and interested in the whole learning progress.

Secondly, the geophysical model from the tectonic model with rock physical parameters is extracted while the other minor factors are discarded. The geophysical model is described as how many geologic units there are and how much resistivity each unit has. In the process, students will learn to grasp the major question from intricate variables and relationship of the project. A proposal with moderate resolution and precision is desirable, however, excessively demand will make students misunderstand the major aim.

Thirdly, forward modelling the electrical data of the geophysical model above according to basic principles and equipment. This process may be an exam alone doing as exercises teaching, which can check students' master levels for basic principles. Students will accomplish it if they can do with the defined procedure as the teacher lectured. However, as the step of original problems method, they will not only do with the defined procedures, but also test various exploration equipment methods and select an optimizing proposal.

Next, geological achievement is constructed based on the interpretation results derived from the forward modelling geophysical data. The step can also be an exercise to check students' master levels about interpretation principles and knowledge. When it is the step of original problems way, the interpretation result can be comparison with the original model abstracted in the first step, which can tell students the final aim of the electrical prospecting. It is not same as the exercise. The exercises teaching method focused on the right answers of questions from geophysical data, however, the original problems method took care of not only the right answers about geophysical data but also the optimizing proposal for the prospect project.

Lastly, students will learn to comprehensive analysis, optimization and proposing feasible advises. They will consider the technology proposal, field operating, and economic cost about the prospect project. They will construct feasible advises of other geophysical methods if the electrical method and data can't acquire the satisfaction proposal expected.

\section{A teaching case with original problems method}

The original problems method will integrate with practical project in order to guiding students learn basic principles and knowledge with huge interesting, so the case teaching is the main feature and property. There are lots of projects of electrical prospect from industry or living. However, moderate abstracting for grasp major tasks is significant when introducing practical cases. The following one will be detail dissected as an application sample of the original problems method.

A coal corporation wonder the distribution of goaves and the amount of water filling in goaves of a mining area. This is a prototype of original problems. Abiding by the principles of the original problems teaching, the teacher guided students to research and describe its geologic structure and physical model firstly. The mining area among the prospecting depth could be divided to three layers, the first is new formation, the second is coal and the last is base rock which is a semi-infinite space. Their values of resistivity are three levels and increasing from top to bottom. The resistivity sounding curve with electrode distance is the A pattern. Where coals were mined became goaves. The sounding curve is the $\mathrm{K}$ pattern if the mining goaf is vacancy not filling of water which resistivity is the air resistivity. It is the $\mathrm{H}$ pattern if there are filling of water in the mining golf. The case of filling of water will be discussed here and parameters of the geophysical model is described as the Table 1. 
The apparent resistivity data were acquired by forward calculating based on the geophysical model using basic electric principles and knowledge. Its curve related is shown in the left of the Fig. 2 and represented the measure data of the case. Seeing from the measure curve, the resistivity characteristic exhibited with the electrode distance increased, the prospecting depth increased too. The curve is just the $\mathrm{H}$ pattern. Through analysis, students will profoundly master the basic theory and its sounding curve of the electrical exploration.

Finally, data inversion was carried on the computer program made by students under the teacher motivation. In the processing, students will learn inversion theory related with interesting, such as least square method, damping coefficient, convergence strategy, and the differences between forward and inversion calculating. Seeing from the right of the Fig. 2, the geologic model expected was acquired by inversion and interpretation. The error is about $0.5 \Omega \mathrm{m}$ of the inversion calculating. The aim of the prospect case was achieved.

Table 1 Parameters about the geophysical model

\begin{tabular}{l|ll}
\hline NO. OF LAYERS & DEPTH $(M)$ & RESISITIVITY $(\Omega . M)$ \\
\hline $\mathbf{1}$ & 10 & 100 \\
$\mathbf{2}$ & 100 & 10 \\
$\mathbf{3}$ & infinite & 300 \\
\hline
\end{tabular}
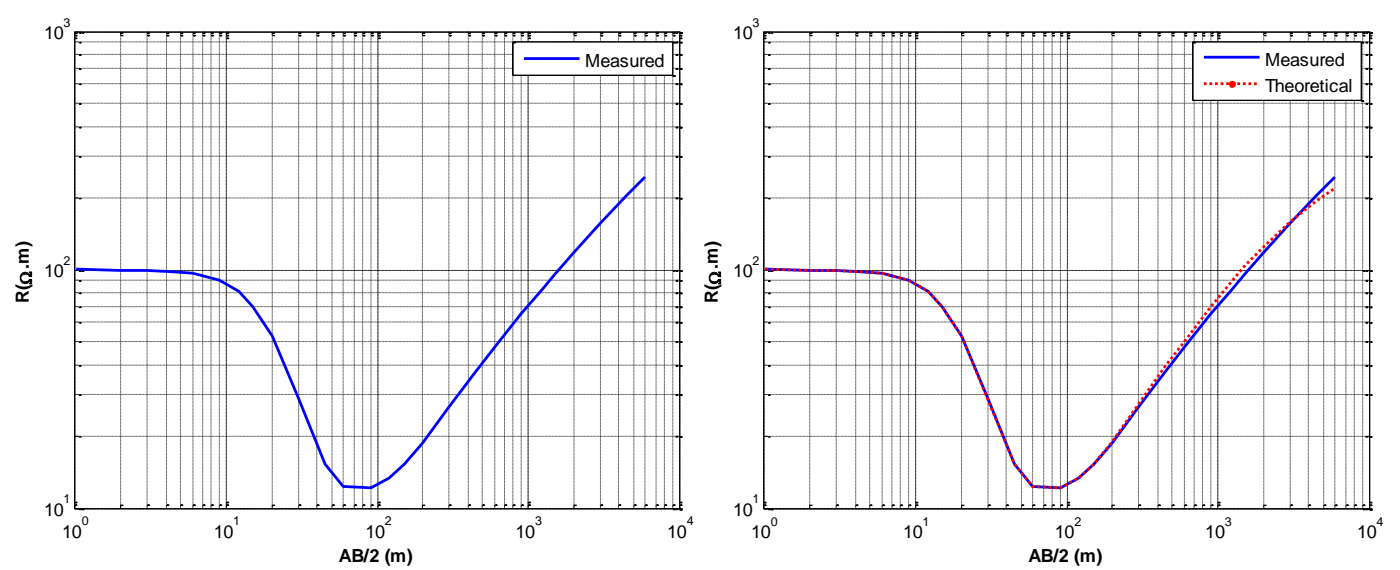

Figure. 2 the sounding curve case (L: measured, R: comparison of measured and theoretical)

\section{Conclusion and discussion}

The exercises teaching can promote and check students' learning basic knowledge. It will make students misunderstand the geophysics and even physics are mathematical calculation if the exercise roles are excessively emphasized and the original phenomenon of exercises are neglected, which will hinder students' innovation training. However, the original problems teaching will not only check students' learning through exercises training, but also guide students analyzing the original phenomenon and applying knowledge acquired to solve practical projects of industry or living. Consequently, students will be more interesting with learning and be improved on innovation, collaboration and active study under the original problems method.

\section{Acknowledgements}

This research is supported by the National Science and Technology Supporting Program (2012BAB13B01), National Key Scientific Instrument and Equipment Development Program (2012YQ030126), Coal United Project of National Natural Science Foundation (U1261203), China Geological Survey Project (1212011220798), National Science and Technology Major Project (2011ZX05035-004-001HZ), and China University of Mining \& Technology (Beijing) Curriculum Construction Project (K140204). 


\section{References}

[1] Zhao KaiHua, Physics education and scientific quality cultivation, College Physics, 8(1995), 2-6.

[2] Liu JinMing, Geoelectric field and electrical exploration methods, Geological Press, Beijing, 2005, pp. 4-5.

[3] Yu KeMing, Discuss the original problem with ability training, College Physics. 5(1997), 44-46, 27.

[4] Xing Hongjun, Original problem teaching: the new horizon of physical education reform, Curriculum, Teaching Material and Method, 5(2007), 51-57

[5] Wang Jing, Xing Hongjun, The characteristics and educational function of original physics problems, Journal of Pingdingshan Teachers College. 5(2004), 96-98.

[6] Hou Jianfang, Xing Hongjun, Chen Qingmei, The original physical problem must be introduced in physical teaching of the middle school, Physics Bulletin, 7(2006), 21-23

[7] Xing Hongjun, Chen Qingmei, Thinking about the original physical problem teaching, Journal of the Chinese Sociaty of Education, 8(2006), 67-69.

[8] Zhou Wulei, Lu Cuijuan, On reform of middle school original physical problem in the modern education era, Qiannan Minzu Shifan Xueyuan Xuebao, 5(2014), 61-65.

[9] Wang Baoqiang, Tian Jiacai, Wang Yinhang, et al. The value and strategy of the original problem introducing in chemistry teaching, Chemistry Education, 11(2014), 23-26.

[10] Zhao KaiHua, Preface, in: Lin ChunZhen, Wu CongShi (Eds.) The successive exam collection for physics graduate study in American colleges (1980-1984), Higher Education Press, Beijing, 1985 , pp. 5.

[11] Yang ZhenNing, Yang ZhenNing collection wroks, East China Normal University Press, Shanghai, 1998, pp. 508. 